\title{
Synthesis of 1-Dimensional CdO Nanostructures and its Heterojunction Diode Characteristics
}

\author{
S. Prabhakaran, B. Gokul and R. Sathyamoorthy* \\ PG and Research Department of Physics, Kongunadu Arts and Science College (Autonomous), \\ Coimbatore 641 029, Tamil Nadu, India; rsathya59@gmail.com
}

\begin{abstract}
1-Dimentional nanostrutured Cadmium Oxide (CdO) thinfilms were prepared on p-type silicon (100) substrates by Chemical Bath Deposition (CBD). Deposition time was varied form $6 \mathrm{hrs}$ to $12 \mathrm{hrs}$ to tune the 1-Dimensitonal nanostructures. CdO thin films deposited for 6 hrs show needle like structures whereas film deposited for 12 hrs show nanowire structure. The XRD pattern confirms the polycrystalline nature of the film. EDAX pattern confirms the elemental species with right stoichiometry. PL spectra show strong emission peak at $511 \mathrm{~nm}$ in all the samples. $\mathrm{n}$-CdO/p-Si heterojunction diode was fabricated and its characteristics were studied. Ideality factor was estimated from I-V measurements and found to be 3.5 and 3.3. This high value of ideality factor arises due to the presence of interface states and series resistance effect.
\end{abstract}

Keywords: Chemical Bath Deposition, Heterojunction Diode, Nanoneedles, Nanowires

\section{Introduction}

Metal-oxide- transparent semiconductors like $\mathrm{SnO}_{2}$, $\mathrm{In}_{2} \mathrm{O}_{3}$, ITO, FTO, and CdO have been used extensively for optoelectronic applications such as solar cells, smart windows, flat panel display and light emitting diodes[1]. One of the elementary devices of modern electronic industry is diode. Hence it is important to fabricate high performance diode for electronic and optoelectronic applications. Cadmium Oxide (CdO) is an II-VI compound n-type degenerate semiconductor with a simple cubicstructure and having a direct band gap of $2.3 \mathrm{eV}$ [2]. Intrinsic $\mathrm{CdO}$ show very low electrical resistivity of about $10^{-2}-10^{-4} \Omega$-cm [3]. 1-Dimensional transparent metal oxide nanostructures with transparency and high electrical conductivity provide wide opportunities in transparent electronic applications. Mostly Heterojunction diodes are fabricated using 1-D $\mathrm{ZnO} / \mathrm{p}-\mathrm{Si}(100)$ which has high transparency, but electrical conductivity is at the order of few $\mathrm{M} \Omega$ [4]. CdO has both visible transmission and high electrical conductivity. Hence heterojunction diode with 1-D CdO nanostructures would provide better performance in electronic and optoelectronic devices. 1-D CdO nanostructures were prepared by wet chemical prepcipitation [5], hydrothermal [6], chemical vapor deposition [7], chemical bath deposition [8] etc. Among the above chemical bath deposition is a simple, cost effective technique and large scale production is also possible.

In this work maiden attempt has been made to prepare 1-D CdO nanostructures by simple chemical bath deposition method and its heterojunction characteristics were studied. To the best of our knowledge there is no report on the Heterojunction diode characteristics are discussed in detail.

\section{Experimental Procedure}

\subsection{Preparation CdO Nanostructures by Chemical Bath Deposition Method}

For the synthesis of cadmium oxide thin films, the used precursors are cadmium nitrate tetra dehydrate and aqueous ammonia. $0.1 \mathrm{M}$ cadmium nitrate was first dissolved in the deionized water and then $5 \mathrm{M}$ of aqueous ammonia 
solution was added. Immediately, the solution turns into turbid white. Excess addition of ammonia to the above, the solution becomes colorless and transparent. Then the cleaned silicon substrates were dipped into the above complex solution for 6 hours and 12 hours at $70^{\circ} \mathrm{C}$ temperature. Then the substrates were taken and rinsed in DI water. Then the samples were annealed at $400^{\circ} \mathrm{C}$ for 1 hour to remove the hydroxide phase if any.

The structural analysis of $\mathrm{CdO}$ thin films were carried out by XRD using Shimadzu-6000 with CuKa radiation $(\lambda=0.154 \mathrm{~nm})$. The surface morphology of the thin films was investigated using JEOL-600 Scanning electron microscopy (SEM) and Compositional analysis was done using EDS. Photolumisecnce spectra was obtained using Flurong. I-V characteristics were studied using 2612A Keithley Source Meter.

\section{Fabrication of Heterojunction Diode}

Figure 1 depicts the schematic diagram of $n-C d O / p-S i$ heterojunction diode. After depositing $\mathrm{n}-\mathrm{CdO}$ nanostructured thin film on $\mathrm{p}-\mathrm{Si}(100)$ substrate, The ohmic contacts of these device was formed by Silver(Ag) paint onto the CdO thin film and to the back surface of silicon, respectively. I-V characteristics of the diode are analyzed using 2612A Keithley Source Meter in the voltage range $-20 \mathrm{~V}$ to $+20 \mathrm{~V}$.

\section{Results and Discussion}

\subsection{Structural Analysis}

Figure $2(\mathrm{a}-\mathrm{c})$ shows the XRD pattern of $\mathrm{Cd}(\mathrm{OH})_{2}$ and $\mathrm{CdO}$ thin films prepared by simple chemical bath deposition method for $6 \mathrm{hrs}$ and $12 \mathrm{hrs}$. $\mathrm{Cd}(\mathrm{OH})_{2}$ samples show amorphous nature. $\mathrm{CdO}$ samples show polycrystalline nature exhibiting face centered cubic crystal structure. The characteristic peaks at $2 \theta=33.04^{\circ}$, $38.3^{\circ}, 55.33^{\circ}$ corresponds to (111), (200) and (220) planes. Increase in deposition time from 6 hrs to $12 \mathrm{hrs}$ the intensities of all the planes increases. The peak at $62^{\circ}$, correspond to the $\mathrm{Si}$ substrates. The crystallite size of sample were calculated from Debye Scherrer's formula; $D=0.9 \lambda / \beta \cos \theta$ where $\lambda$ is $X$-ray wavelength, $\theta$ is the Bragg's angle and $\beta$ is the full width of diffraction line (FWHM) at the half of maximum intensity and

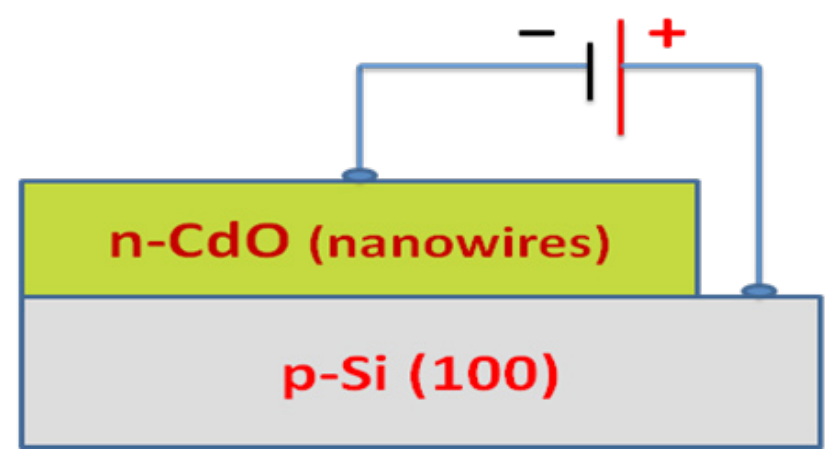

Figure 1. Schematic picture of $\mathrm{Si}(\mathrm{p})-\mathrm{CdO}(\mathrm{n})$ Heterojunction diode.

calculated crystallite size for the sample at $6 \mathrm{hrs}$ was $30 \mathrm{~nm}$ and $12 \mathrm{hrs}$ was $25 \mathrm{~nm}$.

\subsection{Morphological Analysis}

Figure 3(a-c) shows the morphological features of the chemical bath deposited $\mathrm{Cd}(\mathrm{OH})_{2}$ and $\mathrm{CdO}$ thin films for 6 and 12 hrs. Figure 2(a) shows the nanoneedle of length few micrometers when films were deposited for $6 \mathrm{hrs}$ duration. When increasing the deposition time to $12 \mathrm{hrs}$, the needles become smaller in size and align linear to form continuous nanowires. Figure 2 (d) EDAX Spectra of $\mathrm{CdO}$ thin films deposited for $12 \mathrm{hrs}$, its reveals that sample contains only Cd and O peaks, Si peak corresponds to $\mathrm{p}-\mathrm{Si}(100)$ substrate of the samples.

\subsection{Photoluminescence Spectra}

Figure 4 shows the photoluminescence of $\mathrm{CdO}$ thin films deposited for 6 and 12 hrs. Both the samples show strong emission peak at $511 \mathrm{~nm} .511 \mathrm{~nm}$ peak emitted by CdO nanowires is the near band edge emission of CdO. This clearly demonstrates that the samples are pure without impurity.

\section{$4.4 \mathrm{n}-\mathrm{CdO} / \mathrm{p}-\mathrm{Si}(100)$ Heterojunction Diode} Characteristics

Figure 5 shows the diode characteristics of Heterojunction $\mathrm{n}-\mathrm{CdO} / \mathrm{p}-\mathrm{Si}(100)$ prepared for $6 \mathrm{hrs}$ and $12 \mathrm{hrs} \mathrm{respectively.}$ Both the samples show good rectifying behavior with forward-to-reverse current ratio in the range of -20 to $20 \mathrm{~V}$. In forward bias current increases exponentially and for $6 \mathrm{hr}$ deposited samples the threshold voltage is found to be $10 \mathrm{~V}$ and increase in deposition time from 6 to $12 \mathrm{hr}$, threshold energy of the diode decreases to $8.5 \mathrm{~V}$. 


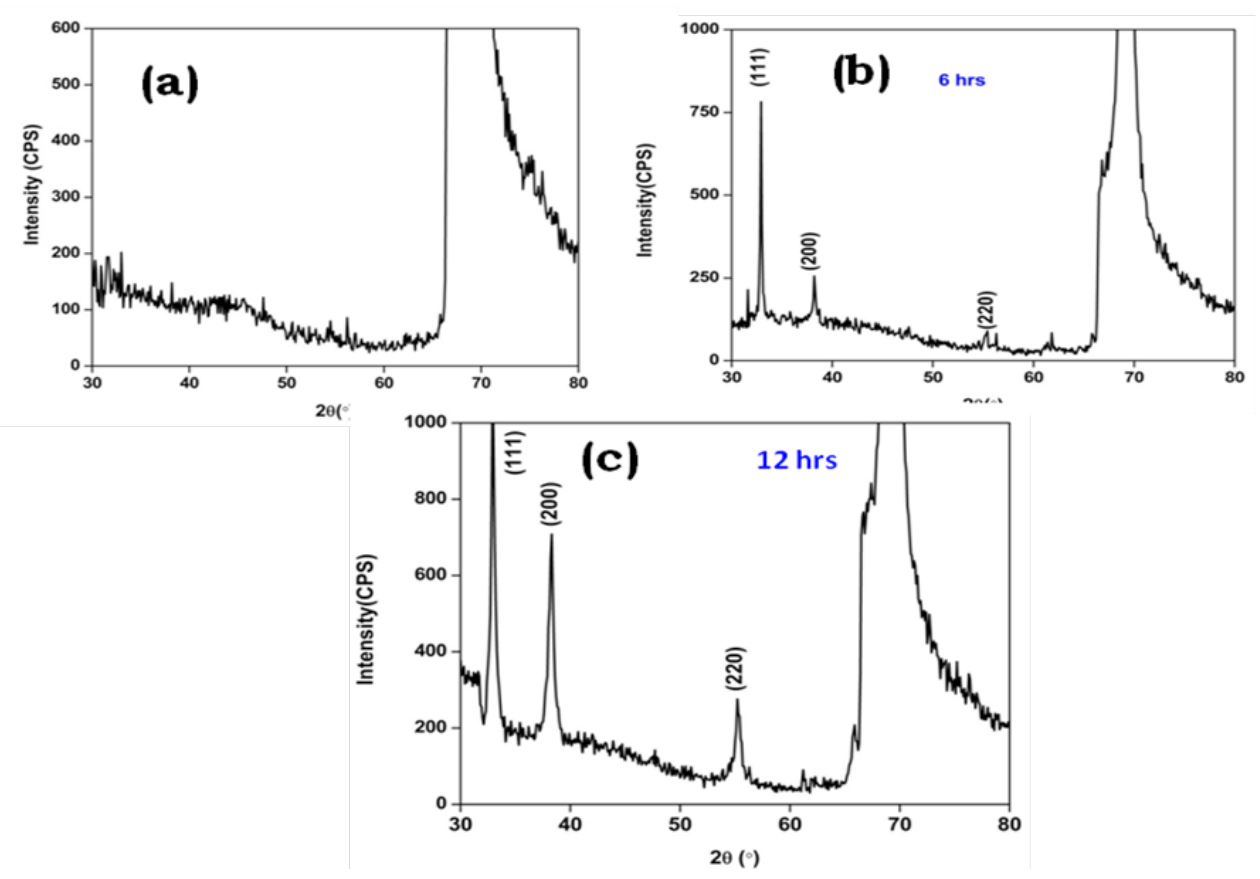

Figure 2. XRD pattern of (a) $\mathrm{Cd}(\mathrm{OH})_{2}$ and $\mathrm{CdO}$ nanostructured thin films deposited for (b) 6 hrs and (c) $12 \mathrm{hrs}$.
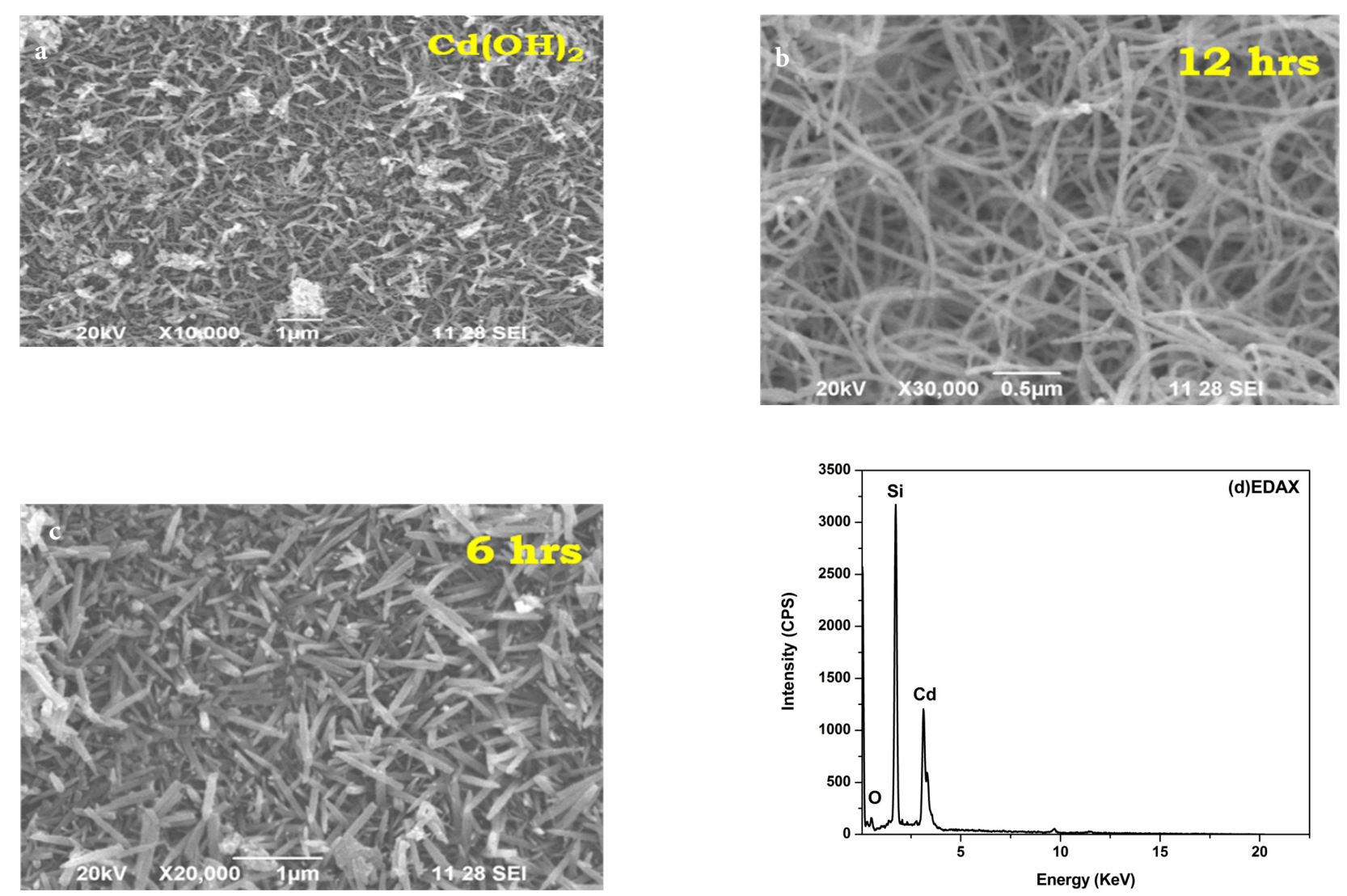

Figure 3. SEM images of (a) $\mathrm{Cd}(\mathrm{OH})_{2}$ and (b)CdO nanostructure thin films deposited for $6 \mathrm{hrs}$ (c) SEM images of CdO thin films deposited for $12 \mathrm{hrs}$ (d) EDAX Spectra of CdO thin films deposited for $12 \mathrm{hrs}$. 


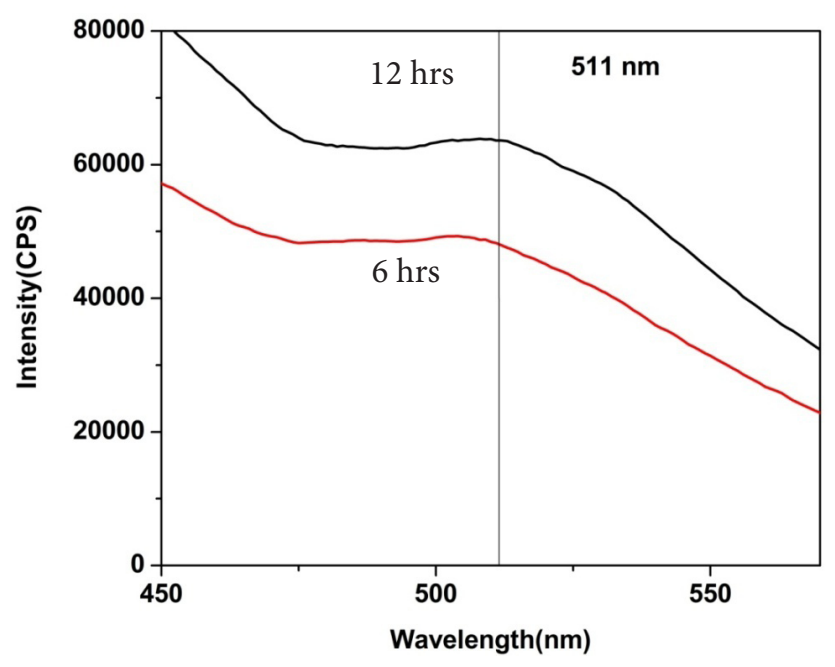

Figure 4. Photoluminescence Spectra of CdO thin films deposited for 6 and 12 hrs.

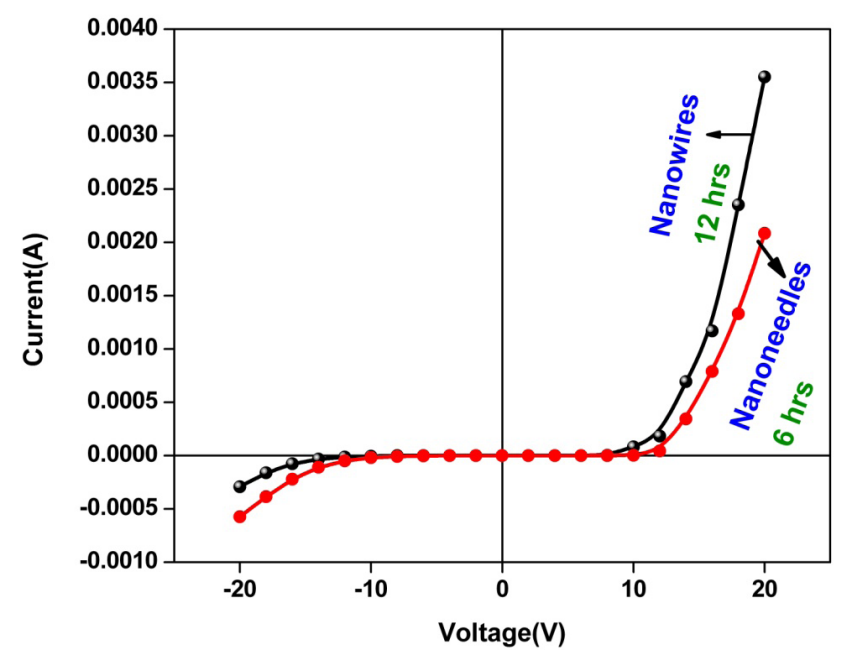

Figure 5. Heterojunction diode Charaterstics of $\mathrm{n}-\mathrm{CdO} /$ p-Si(100) (12 hr deposition).

The diode ideality factor was determined from the slope of the forward bias $\operatorname{lnI}$ vs. $V$ curve [9] using the equation given by

$$
n=\frac{q}{k T} \frac{d V}{d \ln I}
$$

where, $k$ is the Boltzmann constant and $d V / d \ln I$ is the inverse slope of $\ln I$ vs. $V$ curve.

The value of the ideality factor of the $\mathrm{CdO} / \mathrm{p}-\mathrm{Si}$ Heterojunction is determined from the slope of the straight line region of the forward bias log $\mathrm{I}-\mathrm{V}$ characteristics The estimated ideality factor was found to be 3.5 and 3.3 for films deposited at $6 \mathrm{hr}$ and $12 \mathrm{hr}$ respectively. The higher value of ideality factor of the $\mathrm{CdO} / \mathrm{p}$-Si diode is attributed to the interface states and series resistance effects [10].

\section{Conclusion}

$\mathrm{CdO}$ nanoneedles and nanowires were prepared by simple chemical bath deposition method for the deposition time of $6 \mathrm{hr}$ and $12 \mathrm{hr}$. XRD pattern shows the polycrystalline nature of $\mathrm{CdO}$ nanocrystalline thin films.Surface morphology is highly influenced by deposition time (i.e) film deposited 6 hrs shows nanoneedles where as film deposited $12 \mathrm{hrs}$ shows nanowire. Heterojucntion diode was fabricated using $\mathrm{n}-\mathrm{CdO} /$ p-Si(100) layers and ideality factor found to be 3.5 and 3.3 due to interface $\mathrm{SiO}_{2}$ layer formed. The present value of Ideality factor is comparatively less than reported values. Hence it is highly suitable for heterojunction diode fabrication.

\section{References}

1. Saha B., Das S., and Chattopadhyay K. K., "Electrical and optical properties of $\mathrm{Al}$ doped cadmium oxide thin films deposited by radio frequency magnetron sputtering", Sol. Energy Mater. Sol. Cells, vol. 91, p. 1692-1697, 2007.

2. Subramanyam T. K., Rao G. M., and Uthanna S., "Process parameter dependent property studies on $\mathrm{CdO}$ films prepared by DC reactive magnetron sputtering", Mater. Chem. Phys., vol. 69, p. 133-142, 2001.

3. Gurumurugan K., Mangalaraj D., and Narayanadass Sa. K., "Structural characterization of cadmium oxide thin films deposited by spray pyrolysis", J. Cryst. Growth, vol. 147, p. 355-360, 1995.

4. Caglar M., Ilican S., Caglar Y., and Yakuphanoglu F., "Electrical conductivity and optical properties of $\mathrm{ZnO}$ nanostructured thin film", Applied Surface Science. vol. 255, p. 4491-4496, 2009.

5. Liu X., Li C., Han S., Han J., and C. Zhou, "Synthesis and electronic transport studies of $\mathrm{CdO}$ nanoneedles", Appl. Phys. Lett., vol. 82, p. 1950 (3 pages), 2003.

6. Yang Z., Zhong W., Yin Y., Du X., Deng Y., Au C., Du Y., "Controllable synthesis of single-crystalline $\mathrm{CdO}$ and $\mathrm{Cd}(\mathrm{OH})_{2}$ nanowires by a simple hydrothermal approach", Nanoscale Res Lett., vol. 5, p. 961-965, 2010. 
7. Li X., Young D. L., Moutinho H., Yan Y., Narayanswamy C., Gessert T. A., Coutts T. J., "Properties of CdO thin films produced by chemical vapor deposition", Electrochem. Solid-State Lett., vol. 4, p. C43-C46, 2001.

8. Maity H. R., Khallaf K. K., Chenb C. T., Chang L. B., Lupana O., Duttaa A., Heinricha H., Shenouda A., Chow L., "Investigation of chemical bath deposition of CdO thin films using three different complexing agents", Appl. Surf. Sci., vol. 257, p. 9237-9242, 2011.
9. Matheswaran P., Sathyamoorthy R., Asokan K., "Schottky nature of $\mathrm{InSe} / \mathrm{Cu}$ thin film diode prepared by sequential thermal evaporation", Electronic Materials Letters, vol. 8, p. 621-626, 2012.

10. Sathyamoorthy R., Abhirami K. M., Gokul B., Gautam S., Chae K. H., Asokan K., "Fabrication of p-n junction diode using $\mathrm{SnO} / \mathrm{SnO}_{2}$ thin films and its device characteristics", Elec. Mater. Lett. (DOI: 10.1007/s13391-013-3297-6). 